\title{
An Alternative for All-Electric Ships Applications: The Synchronous Reluctance Motor
}

\author{
Ioannis Ch. Proimadis, Dionysios V. Spyropoulos, and Epaminondas D. Mitronikas \\ Electromechanical Energy Conversion, Department of Electrical and Computer Engineering, University of Patras, \\ 26504, Rio, Patras, Greece \\ Correspondence should be addressed to Epaminondas D. Mitronikas; e.mitronikas@ece.upatras.gr
}

Received 26 October 2012; Revised 30 January 2013; Accepted 11 February 2013

Academic Editor: George Antonopoulos

Copyright (C) 2013 Ioannis Ch. Proimadis et al. This is an open access article distributed under the Creative Commons Attribution License, which permits unrestricted use, distribution, and reproduction in any medium, provided the original work is properly cited.

\begin{abstract}
The three-phase synchronous reluctance motor (SynRM) is presented as a possible alternative in all-electric ship applications. The basic features of this motor with regard to the other types of motors are shown. The structure of the motor and specifically the structure of its rotor are analyzed, while the basic operating principles are presented and references on commonly used control strategies are made. In this paper, a demonstration of a reluctance motor fed by a voltage source inverter (VSI) takes place. To demonstrate the operation of the motor fed by a VSI, an example using a scalar control method is implemented, where harmonic injection PWM (HIPWM) is used to drive the VSI. Experimental results on a commercially available motor are shown, focusing on the harmonic content of the current.
\end{abstract}

\section{Introduction}

Sea transportation plays a crucial role in the development of human civilization for more than 5,000 years [1]. This period has been characterized by a constant effort to design and construct faster, more comfortable, and more reliable ships. However, the most significant step towards the modern sailing has been made during the industrial revolution, as it led to drastic changes in the design and operation of the ships, one of which was the use of fossil-fuel-powered engines for their propulsion.

In modern times, the constant progress in electric and electronic systems had also an important effect on ships and led to the first commercial adoption of electricity-driven technology by the cruise ship industry in the late 1980s [2]. In the latest years, an intensive discussion has emerged around the adoption of the pioneering all-electric ships for the industry [3], since they have more advantages than the mechanical transmission-based ships [4]. This discussion subsequently reinforced the interest in high-end power electronics and electric machines that could be used.

Propulsion systems consume the major part of the total energy in conventional ships [5], while in military ships a considerable proportion of this energy is used to power weapon system equipment. Moreover, new, more advanced, and more automated weapon systems are being developed, which will need much greater amounts of energy to operate [6].

From the above, it is obvious that the need for more efficient electric machines in the future ships will not be restricted to those used for the propulsion systems. In every ship, there is a great need for middle- and low-power motors. These are used in a large variety of applications, such as winches, hoists, and pumps for water or fuels. It is also a fact that the navy is considering the replacement of hydraulic systems and other traditionally mechanical systems by powerelectronics-driven electric motors. Also, electric motors are used in combustion air fans, refrigeration plants and ventilation systems. While electric propulsion motors should have a very small weight-to-power ratio, for the large amount of supplementary drive systems needed it is required that an optimum solution concerning efficiency, cost, and performance should be made. It is possible that this optimum solution can be given in the near future by the reluctance motor.

Reluctance motors are considered as a subcategory of synchronous motors with a salient-pole rotor. They differ 
from other types of motors, since their rotor does not have windings and is constructed from inexpensive materials like iron (instead of expensive magnet, like permanent magnet synchronous motors); thus, there is no concern with demagnetization [7].

Although the reluctance motor has a long history [9], its applications were limited until the last decade, mainly due to lower efficiency than permanent magnet synchronous machines and control issues. However, the development of power semiconductor technology, computers, and microprocessors has revived the interest in these machines in the last years.

Early evolution of reluctance motors led to two different types: switched and synchronous reluctance motors. Although a significant progress has taken place concerning design and control of switched reluctance machines [10], progress regarding synchronous reluctance machines (SynRMs) was not so intensive in the past. However, significant research has been conducted in the recent years, since converter-fed SynRMs show some special features and advantages compared to other types of motors [11-13]:

(i) their stator is identical to that of an induction motor, so the stator can be constructed in the already available assembly line.

(ii) They can achieve high power densities in regard to their size.

(iii) They can function without a starting cage, since they can start in synchronous mode.

(iv) Compared to the induction motor, the SynRMs achieve high torque output in regard to iron losses and higher efficiency [11, 12].

The exploitation of these characteristics of SynRM in applications is still on the way, with many of these focusing on hybrid electric vehicles [13]. More extended research has been conducted in this field with the use of switched reluctance and permanent magnet motors [14, 15]; however, the aforementioned features of SynRM indicate that these could be used in the future, in applications that currently use these two motors.

Moreover, the most appropriate converter topologies should be examined, which will lead to adequate performance of the reluctance machine. As far as converter topologies for use in ship applications are concerned, Controlled Rectifier, Load Commutated Inverter, Cycloconverter, and Voltage Source Inverter are the most popular ones [1, 16-22]. The latter is the most prominent topology for the future of allelectric ships and also the most appropriate topology for the control of SynRM. Voltage source inverter (VSI) uses the pulse width modulation (PWM) technique and it is based on power devices with controlled turn-off, such as IGBTs.

In this paper, the performance of SynRM will be studied through the utilization of a simple PWM control method. This control scheme will be applied on a mass-production motor, and attention to the harmonic content of the current which is the main cause for torque ripples will be paid.

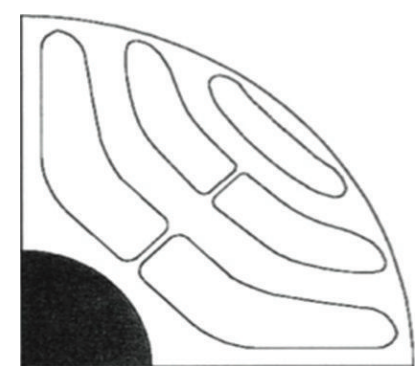

(a)

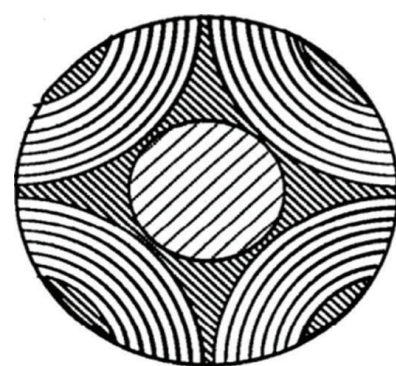

(b)
Figure 1: Two different rotor designs (transverse and axially laminated rotor).

\section{Analysis of the Synchronous Reluctance Motor}

2.1. Structure of Synchronous Reluctance Motor. As it has been already mentioned, the stator of a SynRM is identical to the stator of an induction machine. The construction of the rotor, however, is more complex. In general, the main concept for the construction of the SynRM is the optimization of the rotor in order to maximize the produced (reluctance) torque. The evolution of the SynRM rotors has led to diverse structures, as it is shown in the Figure 1, but a common attribute of all these is the high rotor field anisotropy $[8,23]$.

The individuality of the SynRM's rotor has led to limited adoptions from the industry. This is more characteristic for the axially laminated rotor, although the high $L_{d} / L_{q}$ ratio that can be achieved attracted the interest of many researches. On the other hand, transverse laminated rotors are more appropriate for mass production, are rotor core-loss free, and the air-gap harmonics can be subdued through a sophisticated design. More general, the industrial manufacturing of SynRM has to balance between easy, cheap construction of the rotors and efficiency (low current harmonics, reduction of core loss, and low torque ripple). As this paper is focused on practical applications of SynRM, a mass-production motor will be investigated in Section 4.

2.2. Basic Operating Principles. As it is well known, the stator windings generate a spatial sinusoidally distributed magnetomotive force (MMF) in the air-gap between stator and rotor. The rotor of SynRM is constructed by ferromagnetic steel and nonmagnetic laminations. Despite the absence of field winding in the rotor, the rotor due to the presence of flux paths (Figure 1) distorts the flux density distribution that is produced by the sinusoidally distributed $\mathrm{mmf}$. A simplified interpretation of the produced torque that forces the rotor to rotate at the synchronous speed (the speed of the field in the airgap) lies in the fact that the flux density tends to align the domains in the ferromagnetic rotor. Due to the rotor field distribution, this is equal to the alignment of the leastreluctance axis with the mmf, or, according to Figure 2, the alignment of $d$-axis with $F$ vector. However, because of the equal rotation speed of both vectors, the distance between $d$ axis and $F$ remains constant. 


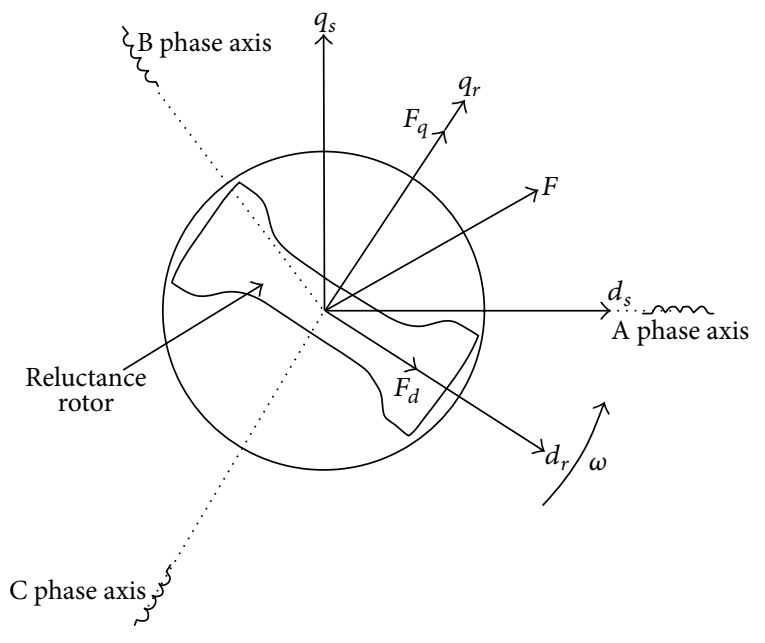

FIGURE 2: $d-q$ analysis of SynRM [8].

2.3. Mathematical Equations. In order to have a comprehensive representation of SynRM, it is significant to present the equivalent circuits (Figure 3 ) and the mathematical model of the machine.

For this reason, the equations are expressed in $d$ - $q$ axes, since $d-q$ system leads to more simplified equations and also to a better understanding of the machine's dynamics.

The corresponding equations in the rotor reference frame are the following [8]:

$$
\begin{aligned}
& V_{d}=r_{s} i_{d m}+L_{d}\left(\frac{d i_{d m}}{d t}\right)-\left[1+\left(\frac{r_{s}}{r_{m}}\right)\right] \omega_{r} L_{q} i_{q m}, \\
& V_{q}=r_{s} i_{q m}+L_{q}\left(\frac{d i_{q m}}{d t}\right)+\left[1+\left(\frac{r_{s}}{r_{m}}\right)\right] \omega_{r} L_{d} i_{d m},
\end{aligned}
$$

where $i_{d m}$ and $i_{q m}$ are given by

$$
\begin{aligned}
& i_{d m}=i_{d}+i_{d c}=i_{d}+\left(\frac{\omega_{r} L_{q} i_{q m}}{r_{m}}\right), \\
& i_{q m}=i_{q}-i_{q c}=i_{q}-\left(\frac{\omega_{r} L_{d} i_{d m}}{r_{m}}\right),
\end{aligned}
$$

where $V_{d}, V_{q}$ are the voltages in direct $(d)$ and quadrature $(q)$ axes, $i_{d}, i_{q}$ are the currents in $d$ and $q$ axes, $\omega_{r}$ is the rotational speed of the frame, $L_{d}$ and $L_{q}$ are the inductances in $d$ and $q$ axes, and $r_{m}$ is an equivalent stator iron loss resistance.

The developed torque is given by the following equation:

$$
T_{e}=\left(\frac{3 p}{2}\right)\left(L_{d}-L_{q}\right) i_{d m} i_{q m}
$$

From the previous analysis of SynRM, we can make some useful conclusions about the role of the inductances $L_{d}$ and $L_{q}$. From (3), we can derive that a high value in the difference $L_{d}-L_{q}$ leads to a high maximum torque. Also, is can be proved that the power factor is mainly affected by the $L_{d} / L_{q}$ ratio. Subsequently, it is clear that the SynRM should be designed in such a way that the highest possible value of $L_{d}$ and the lowest $L_{q}$ are achieved [8,23-26]. Nonetheless, there are limits for theses values, since structural restrictions have to be met.

2.4. Control Strategies for Synchronous Reluctance Motor. The main characteristics that differentiate this type of motor from other types, such as synchronous and induction motors, are the absence of field winding on the rotor and the fact that there is no rotation slip. Many control methods (more or less complicated) have been proposed for this motor along the years $[7,8,24,25,27,28]$.

In order to have a simple block diagram of a scalar control method for the SynRM, the open-loop $V / f$ control of the rotor speed rotation speed is presented in Figure 4.

The user can set the desired speed and this command is translated to the corresponding voltage signals through a function generator, for example, a microcontroller. These signals are driven to a 3-phase PWM inverter, which is presented in the following chapter. The 3-phase inverter is fed by DC voltage, which is produced through a rectifier topology [24]. Finally, the output voltages are driven to the 3-phase motor and force the rotor to rotate with the desired speed.

\section{Voltage Source Inverters}

The three-phase VSI topology consists of six power switches (e.g., IGBTs), which are controlled by six corresponding signals (Figure 5).

As it has been already mentioned, PWM techniques are used for the production of the output voltages in a VSI. The main purpose of the VSI is to produce a fundamental voltage harmonic with controlled rms value and frequency.

A properly designed PWM VSI offers the following characteristics:

(i) high switching frequency, which leads to smaller passive harmonic filters;

(ii) precise regulation of the fundamental harmonic frequency and rms value;

(iii) reduced high-order harmonic content.

Many PWM techniques have been proposed along the years, which in general aimed at the optimization of the harmonic content, better exploitation of the DC voltage source, and reduction of switching losses [29, 30].

Among them, one of the simplest but also the most popular one is the Sinusoidal PWM (SPWM) technique, where three-phase sinusoidar reference signals are compared with a triangular waveform. The corresponding output for each phase is positive when the value of the sine wave is greater than the value of the triangle, and zero in the opposite case. If we denote by $m_{a}$ the $V_{\text {sine, } \max } / V_{\text {triangle,max }}$ ratio, then the resulting maximum value of the line voltage is equal to $V_{\text {line,rms }}=0.866 m_{a} V_{i}\left(m_{a} \leq 1\right)$.

Harmonic injection PWM (HIPWM) is a modification of SPWM, where the 3 sine waves contain additionally a small percentage of 3 rd and 9th harmonics of the fundamental 


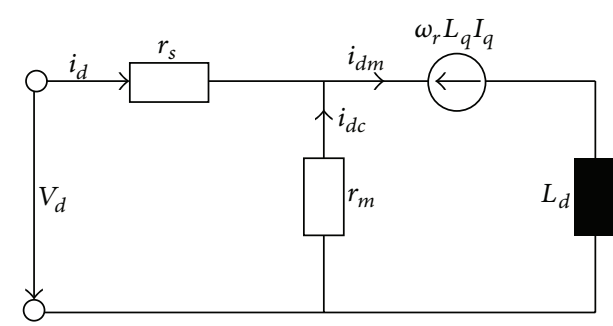

(a)

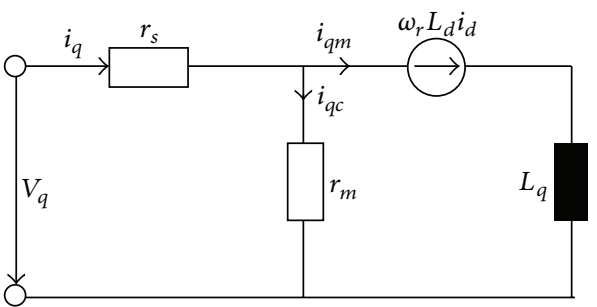

(b)

FIGURE 3: Equivalent circuits of SynRM in rotor reference $d$ (a) and $q$ frame (b) [8].

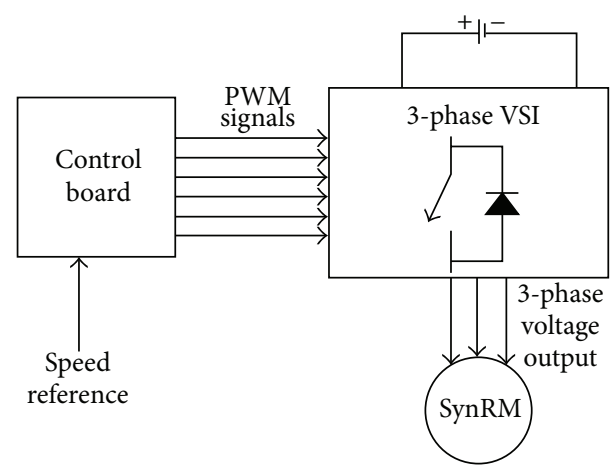

Figure 4: Open-loop control of a SynRM.

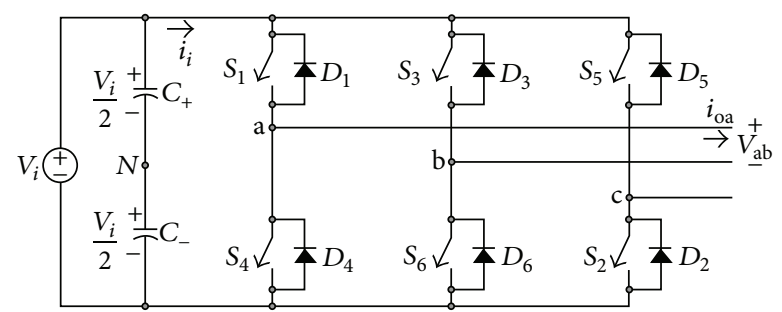

FIGURE 5: VSI topology.

frequency. This modification leads to better exploitation of the input DC voltage, resulting in higher maximum line, as shown in Figure 6.

To evaluate the operation of the selected HIPWM technique, a three-phase inverter has been simulated using appropriate software and a comparison of the classic SPWM and the HIPWM technique was done. In Figure 6(a), the output line voltage and its harmonic content using the SPWM technique is presented, while in Figure 6(b) the corresponding results using the HIPWM technique are demonstrated. In both cases, the inverter's input DC voltage is equal to $400 \mathrm{~V}$. Using the SPWM, the output voltage is $344.6 \mathrm{~V}$ and the THD is $68.59 \%$. These values are improved using the HIPWM, as the output voltage is $396.4 \mathrm{~V}$ and the THD decreases to $52.81 \%$ compared to the previous case. For this reason, the HIPWM technique has been used to drive the inverter in the experimental investigation that follows.

\section{Experimental Setup and Results}

4.1. Experimental Setup. An inverter with the same basic characteristics and operating with the same HIPWM method as in the simulation has been designed and constructed the main components of the experimental device are shown in Figure 7.

The inverter uses IGBTs as switching elements, since they offer low on-state impedance and adequate switching characteristics [24]. A dsPIC30f4011 microcontroller, programmed in $\mathrm{C}$ language, was chosen for the production and control of PWM pulses. The dsPIC peripherals that have been used are analog inputs, which are used in order to read the desired rotation speed (speed reference), digital inputs, one of which is used for ON/OFF function, and a PWM module, which produces the six required control signals for the pulse width modulation of the VSI Bridge. The flow diagram of microcontroller for an open-loop control scheme is given in Figure 8.

For the experiments, a 4-pole SynRM constructed by Kaiser Motoren is used. Its rotational speed can vary between 150 and $1500 \mathrm{rpm}$ and the nominal power at $50 \mathrm{~Hz}$ is $1.26 \mathrm{~kW}$. The rotor of this mass-production motor shows great interest because of its design and construction. It is made from ferromagnetic steel and aluminium alloy, as it is shown in Figure 9. The latter forms a damping cage, which enables the asynchronous starting of the motor by simply connecting the stator to the three-phase network. Additionally, it contributes to the reduction of the oscillations on the rotor. Of course, synchronous starting through an inverter topology is also possible, similarly to SynRM.

For evaluating the performance of the system, experimental results have been carried out at no-load condition. This way, a "worst-case scenario" is examined, as oscillations are greater at no-load condition.

4.2. Experimental Results. In Figure 10, the pulses of an IGBT in the three-phase VSI which is modulated by HIPWM technique are shown.

As it is mentioned, in the experiments an investigation of the current harmonics has been performed. In Figure 11, the current harmonics are presented, in the case of direct connection to the three-phase network. It is clear that the main higher harmonics are the 5th and the 7th, namely, at $250 \mathrm{~Hz}$ and $350 \mathrm{~Hz}$. 


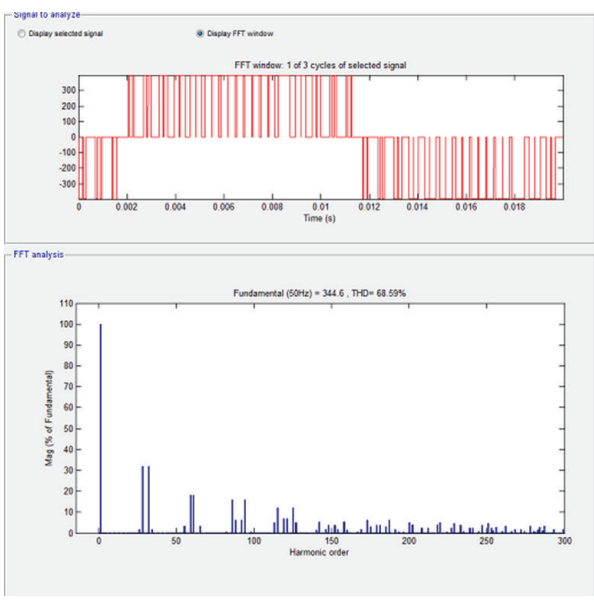

(a)

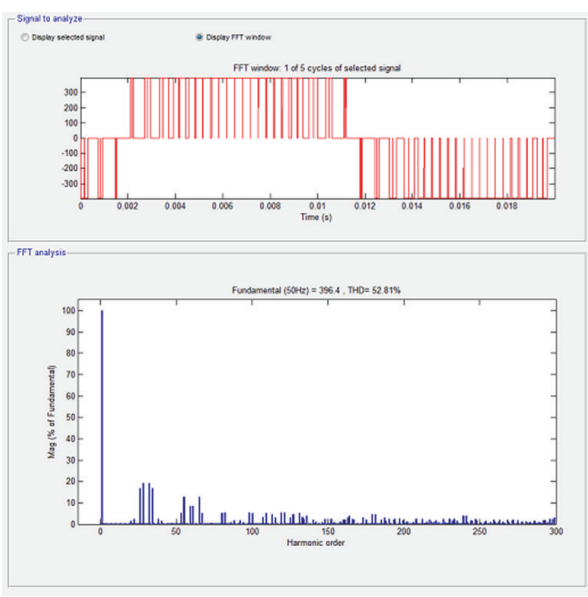

(b)

Figure 6: (a) SPWM and (b) HIPWM voltage signal and FFT analysis.

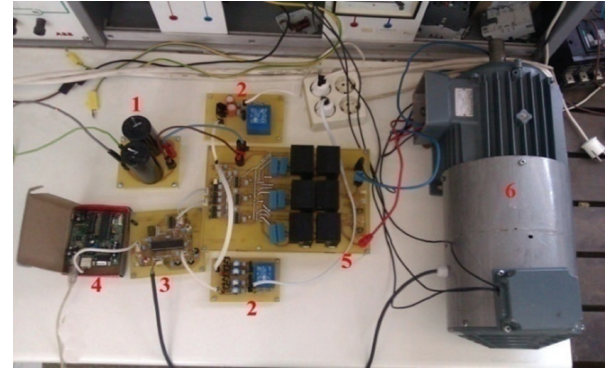

FIGURE 7: Main components of inverter topology. (1) DC link capacitors, (2) $+5 \mathrm{~V}$ and $+15 \mathrm{~V}$ DC supply, (3) control board (Dspic30f4011), (4) Development Board, (5) 3-Phase inverter, and (6) SynRM.

When the topology shown in Figure 7 is used, the rotational speed of the rotor can be adjusted by controlling the corresponding analog input signal of the microprocessor. For the experiments shown, a constant $V / f$ control method was used. As far as the PWM method is concerned, HIPWM was used due to its features which were mentioned before.

With the reference speed set at $50 \mathrm{~Hz}$, the resulting harmonic content of the current is shown in Figure 12. It is clear that, in this case, the main higher harmonics are the 5 th and the 7 th too, while in general all the other harmonics have higher amplitude compared to the direct connection to the three-phase network. Subsequently, the 5th and 7th harmonics are characteristic frequency components of the stator current, induced by the air gap MMF due to the stator winding distribution. With the reference speed set on $25 \mathrm{~Hz}$, the resulting current waveform and harmonic content are shown in Figures 13 and 14. The harmonics are mainly caused by the rotor field anisotropy due to the construction characteristics of the rotor as it can be seen in Figure 9. Additionally, the torque ripple that is characteristic for this motor (according to the manufacturer) contributes to the rise of the energy contained in higher-order harmonics.

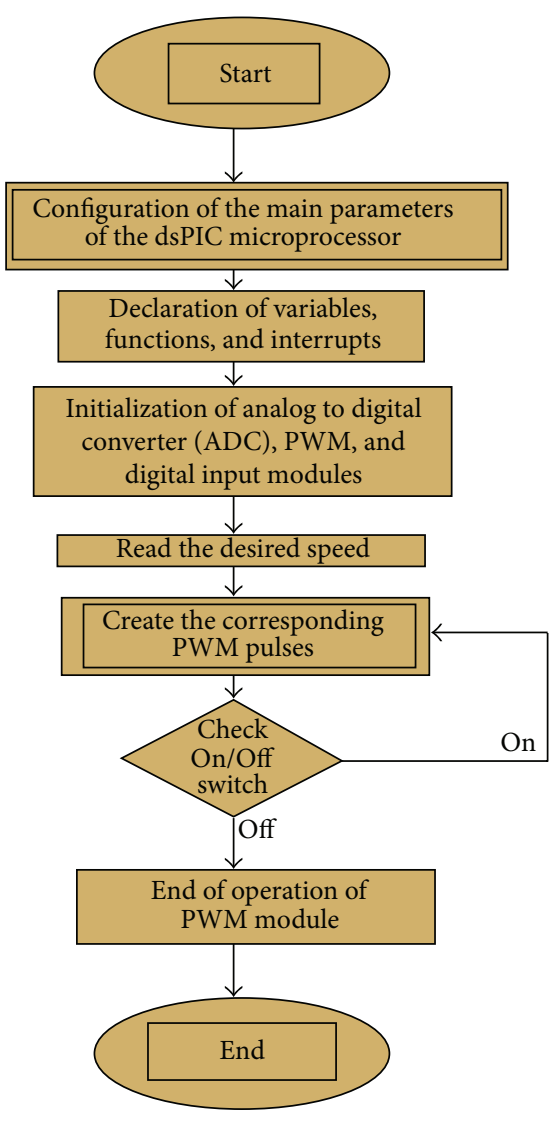

FIGURE 8: Flow chart of the developed open-loop control technique.

\section{Conclusions}

A study on the synchronous reluctance motor has been made in this paper. The experimental results have verified the smooth and precise performance of the motor at $50 \mathrm{~Hz}$. Furthermore, it has been observed that the energy 


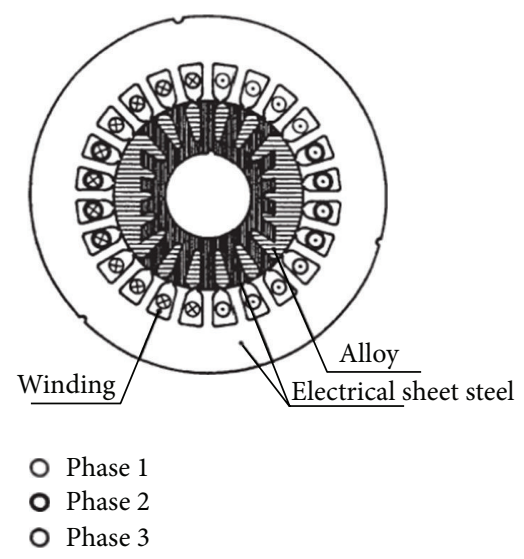

FIGURE 9: Sketch of the SynRM under investigation.

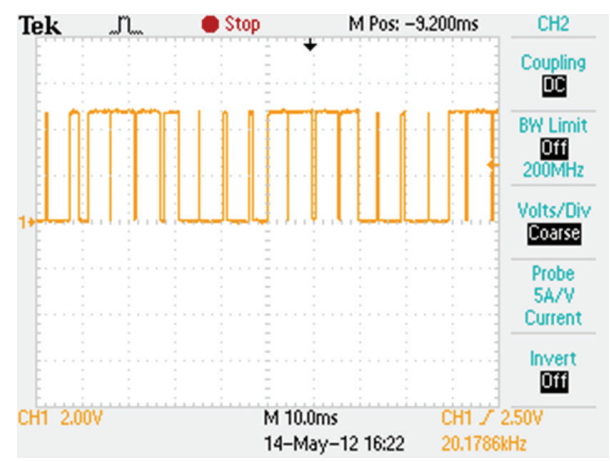

Figure 10: HIPWM gate signal.

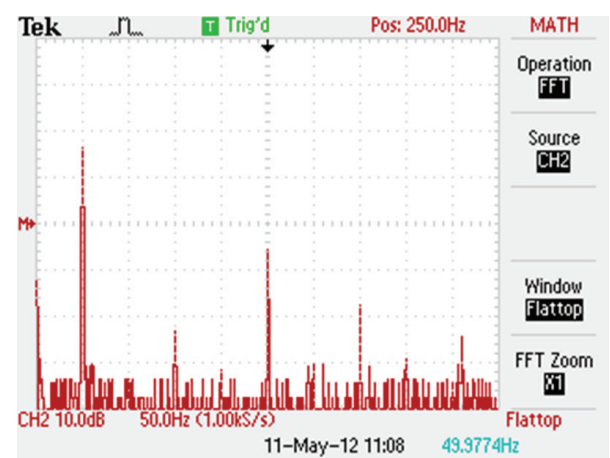

FIGURE 11: Current harmonics when the motor is fed by the utility grid.

of the higher-frequency current harmonics at low speeds, such as $25 \mathrm{~Hz}$, becomes noticeable. To improve performance, a more sophisticated control method for mass-production SynRMs has to be sought. To this direction, the adoption of control methods already available for other synchronous motors has to be considered. In any case, the possibility of using SynRM in all-electric ship applications is subject to further study, since the characteristics of this type of motor show a great promise for the future.

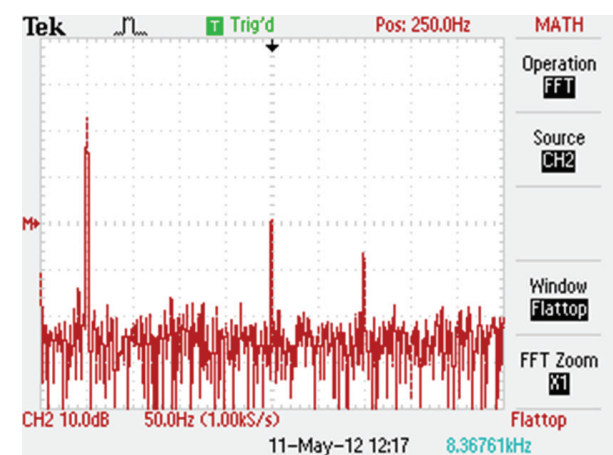

FIgURE 12: Current harmonics at $50 \mathrm{~Hz}$ (fed by a VSI).

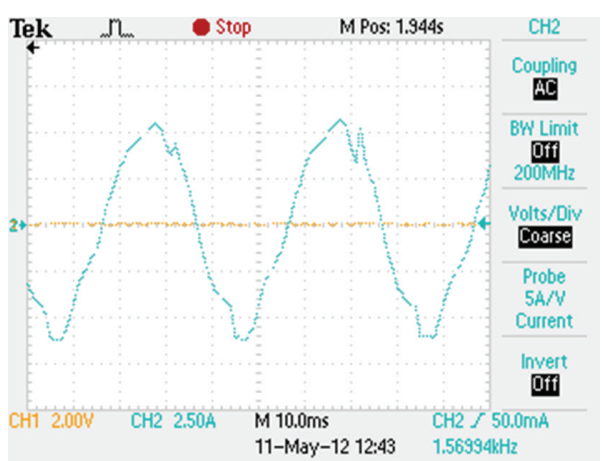

FIgURE 13: Current Waveform at $25 \mathrm{~Hz}$ (actual speed $746 \mathrm{rpm}$ ).

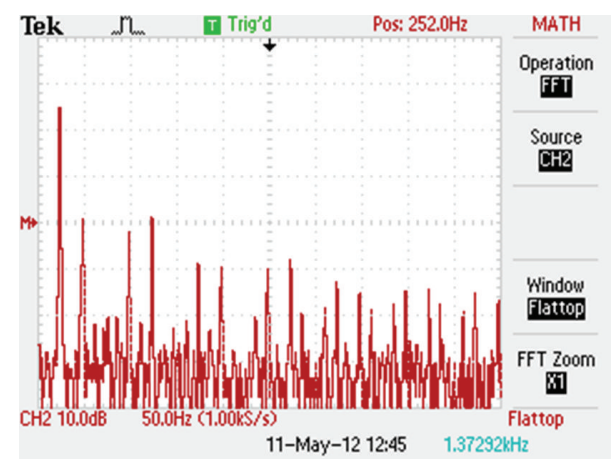

FIGURE 14: Harmonic content of current at $25 \mathrm{~Hz}$ (fed by the VSI).

\section{Nomenclature}

\section{Variables}

$i: \quad$ Current

$V$ : Voltage

$\omega_{r}:$ Rotational speed of the rotor

$L:$ Inductance

$T_{e}$ : Electromagnetic torque

$\lambda$ : Flux

$P$ : Pole pairs

$R_{s}$ : Stator resistance

$F$ : MMF force. 
Subscripts

$d, q$ : Components of a space phasor in $d, q$ frame

$s, r$ : Stationary and rotating frame, respectively.

\section{References}

[1] L. Casson, Travel in the Ancient World, The Johns Hopkins University Press, 1994.

[2] B. Wagner, All-Electric Ship Could Begin to Take Shape By 2012, NDIAs Business and Technology Magazine, 2007.

[3] E. D. Mitronikas and E. M. Tatakis, "Migrating the experience of industrial systems to electric ships: propulsion motors and fault detection," in Proceedings of the 1st MARINELIVE International Workshop on Electric Machines and Power Converters, Athens, Greece, January 2012.

[4] C. G. Hodge, D. J. Mattick, and D. J., "The Electric Warhip," Trans IMarE, vol. 108, Part 2, pp. 109-125, 1996.

[5] W. J. Kruijt, An Integrated Approach to an All-Electric Cruise Vessel, Business Briefing, Global Cruise, 2004.

[6] T. J. McCoy, "Trends in ship electric propulsion," in Proceedings of the IEEE Power Engineering Society Summer Meeting, pp. 343346, July 2002.

[7] H. A. Zarchi, G. R. A. Markadeh, and J. Soltani, "Direct torque and flux regulation of synchronous reluctance motor drives based on input-output feedback linearization," Energy Conversion and Management, vol. 51, no. 1, pp. 71-80, 2010.

[8] J. B. Im, W. Kim, K. Kim, C. S. Jin, J. H. Choi, and J. Lee, "Inductance calculation method of synchronous reluctance motor including iron loss and cross magnetic saturation," IEEE Transactions on Magnetics, vol. 45, no. 6, pp. 2803-2806, 2009.

[9] T. J. E. Miller, Electronic Control of Switched Reluctance Machines, Newnes Publication, 2001.

[10] R. Krishnan, Switched Reluctance Motor Drives, CRC Press, 2001.

[11] T. A. Lipo, "Synchronous reluctance machines. A viable alternative for ac drives?" Electric Machines and Power Systems, vol. 19, no. 6, pp. 659-671, 1991.

[12] A. Boglietti and M. Pastorelli, "Induction and synchronous reluctance motors comparison," in Proceedings of the 34th Annual Conference of the IEEE Industrial Electronics Society (IECON '08), pp. 2041-2044, November 2008.

[13] A. A. Arkadan, N. Al-Aawar, and A. A. Hanbali, "Design optimization of SynRM drives for HEV power train applications," in Proceedings of the IEEE International Electric Machines and Drives Conference (IEMDC '07), pp. 810-814, May 2007.

[14] C. C. Chan, "The state of the art of electric, hybrid, and fuel cell vehicles," Proceedings of the IEEE, vol. 95, no. 4, pp. 704-718, 2007.

[15] N. Schofield, S. A. Long, D. Howe, and M. McClelland, "Design of a switched reluctance machine for extended speed operation," IEEE Transactions on Industry Applications, vol. 45, no. 1, pp. 116-122, 2009.

[16] V. M. Moreno and A. Pigazo, "Future trends in electric propulsion systems for commercial vessels," Journal of Maritime Research, vol. 4, no. 2, pp. 81-100, 2007.

[17] C. G. Hodge and D. J. Mattick, "The Electric Warship II," in Trans IMarE, vol. 109 of Part 2, The Institute of Marine Engineers, 1997.
[18] C. G. Hodge and D. J. Mattick, "The Electric Warship III," in Trans IMarE, vol. 110 of Part 2, The Institute of Marine Engineers, 1998.

[19] C. G. Hodge and D. J. Mattick, “The Electric Warship IV," Trans IMarE, vol. 111, Part 1, pp. 25-30, 1999.

[20] C. G. Hodge and D. J. Mattick, “The Electric Warship V," in Trans IMarE, vol. 112 of Part 2, The Institute of Marine Engineers, 2000.

[21] C. G. Hodge and D. J. Mattick, "The Electric Warship VI," in Trans IMarE, vol. 113 of Part 2, The Institute of Marine Engineers, 2001.

[22] J. M. Prousalidis, N. D. Hatziargyriou, and B. C. Papadias, "On studying ship electric propulsion motor driving schemes," in International Conference on Power Systems Transients (IPST '01), Paper 82, pp. 24-28, Rio de Janeiro, Brazil, June 2001.

[23] H. A. Toliyat and G. B. Kliman, Handbook of Electric Motors, CRC Press, 2nd edition, 2004.

[24] M. H. Rashid, Power Electronics Handbook, Academic Press, 2nd edition, 2001.

[25] I. Boldea, Z. X. Fu, and S. A. Nasar, "Torque vector control (TVC) of axially-laminated anisotropic (ALA) rotor reluctance synchronous motors," Electric Machines and Power Systems, vol. 19, no. 4, pp. 533-554, 1991.

[26] K. B. Bose, Modern Power Electronics and AC Drives, Prentice Hall, 2001.

[27] R. Morales-Caporal and M. Pacas, "A predictive torque control for the synchronous reluctance machine taking into account the magnetic cross saturation," IEEE Transactions on Industrial Electronics, vol. 54, no. 2, pp. 1161-1167, 2007.

[28] T. Matsuo, A. El-Antably, and T. A. Lipo, "A new control strategy for optimum-efficiency operation of a synchronous reluctance motor," IEEE Transactions on Industry Applications, vol. 33, no. 5, pp. 1146-1153, 1997.

[29] M. A. Boost and P. D. Ziogas, "State-of-the-art carrier PWM techniques: a critical evaluation," IEEE Transactions on Industry Applications, vol. 24, no. 2, pp. 271-280, 1988.

[30] S. Jeevananthan, R. Nandhakumar, and P. Dananjayan, "Inverted sine carrier for fundamental fortification in PWM inverters and FPGA based implementations," Serbian Journal of Electrical Engineering, vol. 4, no. 2, pp. 171-187, 2007. 

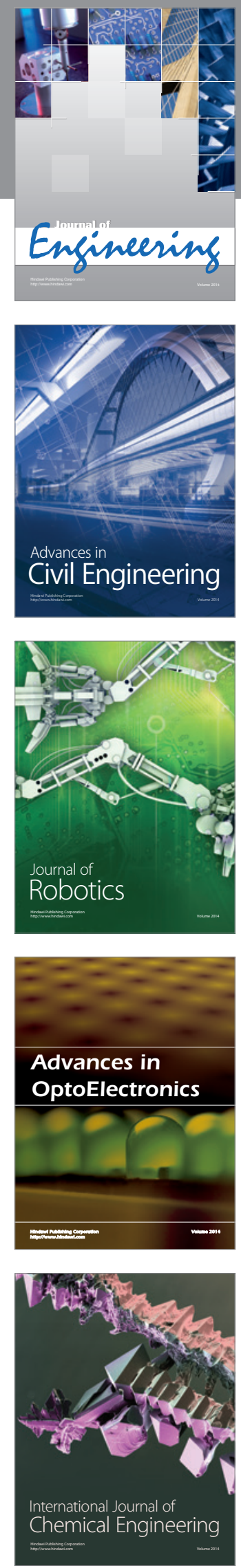

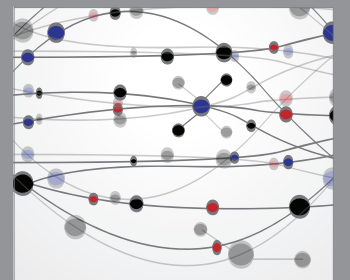

The Scientific World Journal
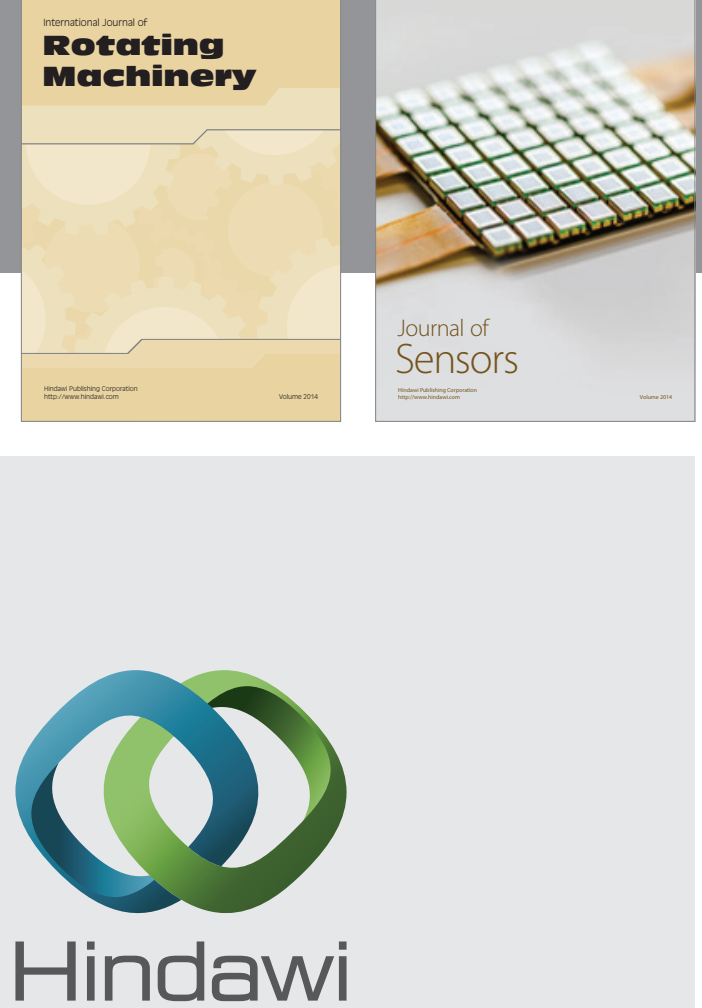

Submit your manuscripts at http://www.hindawi.com
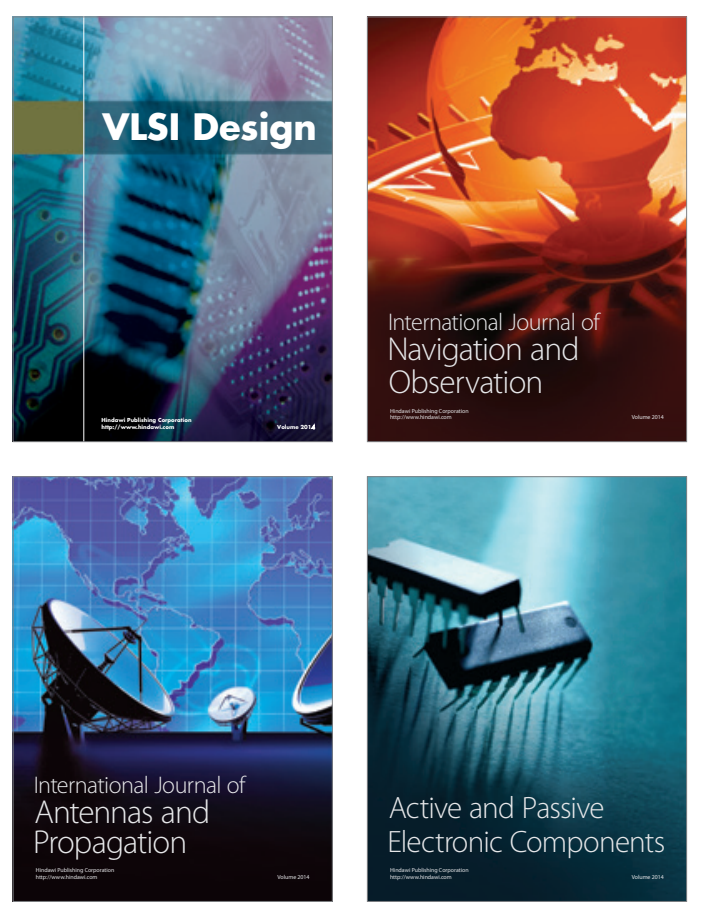
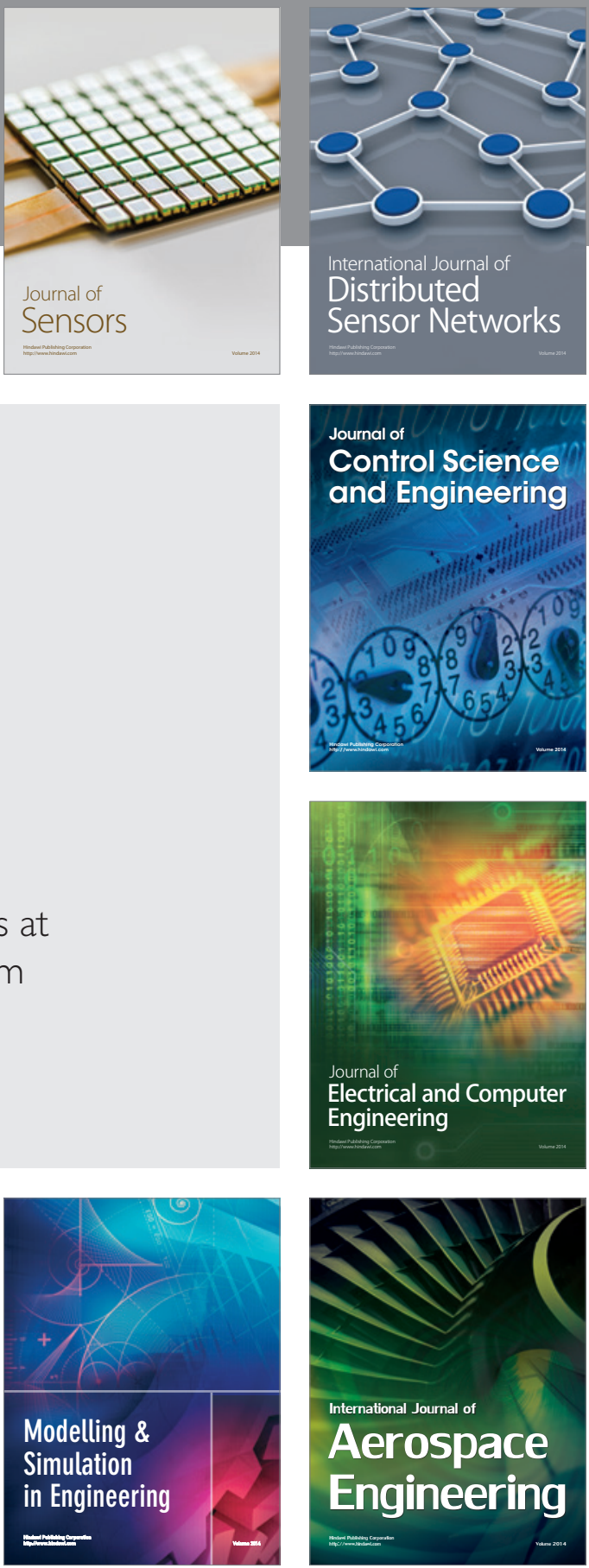

Journal of

Control Science

and Engineering
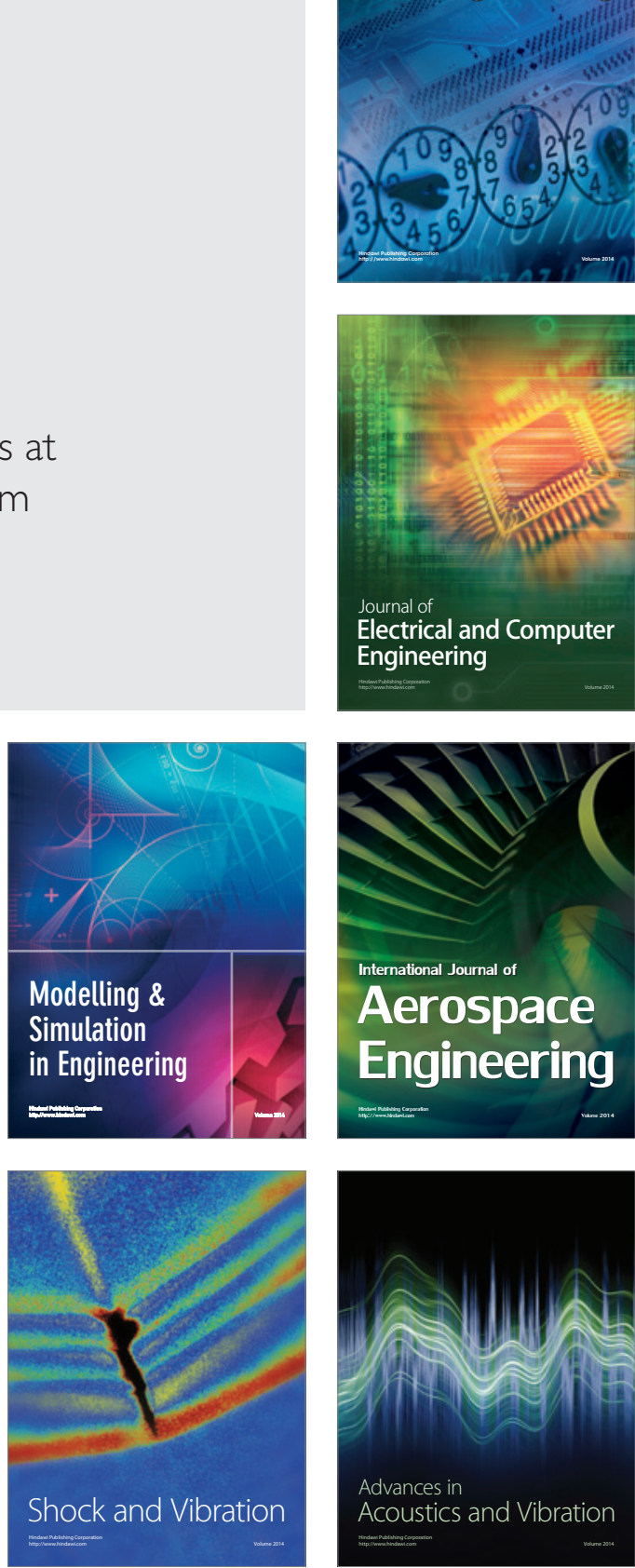